\title{
LACK OF TRANSPARENCY AND FREEDOM OF INFORMATION IN PAKISTAN: AN ANALYSIS OF GOVERNMENT'S FUNCTIONING AND REALISTIC POLICY OPTIONS FOR REFORM
}

\author{
Tahira Mumtaz \\ Assistant Professor, Department of Politics \& International Relations, \\ University of Sialkot, Punjab, Pakistan \\ Sumbal Tariq \\ PhD Scholar, University of the Punjab, Lahore, Pakistan \\ tahirashahz84@gmail.com
}

\begin{abstract}
Pakistan is in grave need of transparency and freedom of information. The public expects policymakers to design policies and device measures to give them the right to look into the public records and track corruption. However, transparency and freedom of information are not much debatable topics in Pakistan. The objective of this study is to highlight the importance of a transparent political process and bring into light the loopholes existing in Pakistan. When it comes to the public's rights, they are only aware of five fundamental living rights: food, education, clothing, shelter, and the right to live. The majority of Pakistani Public have no idea of right to education as they consider it a secondary need. Transparency and freedom of information are imperative for any country to reduce corruption and ensure good governance. When the authorized parties know that they are being tracked and observed by the public (which is the ultimate authority to elect any government), their level of efficiency and honesty in performance becomes high. This research aims to highlight the importance of transparency and analyze the reasons that hinder Pakistan's fair and transparent political process. This research accentuates the issue and finds out some solutions and ordinances passed in the near past as it is imperative to shed light on creating awareness among the masses for the better future of Pakistan.
\end{abstract}

Keywords: Government, Institutions, Public, Good Governance, Information, Transparency, Political Parties, Secrecy

\section{INTRODUCTION}

Pakistan is a democratic country where the public has the ultimate authority to elect their government. In Pakistan, political parties do not hold the designated authority and power they should have. The reason is the civil-military bureaucracy domination, prevailing in the country for decades. This research refers to the parliamentary institutes that are not capable of performing some of their duties mentioned in the code of conduct. Resultantly, the government and related authorities perform operations of their own will and there is no one to question them as there is no proper concept of transparency (Helms, 2012). The government and all of its' respective departments are working with the non-participatory and secrecy prevailing culture. The public has elected them, yet they don't give any attention to their government actions and policies towards country and national assets. They can only see and know what government wants them to see and know. The public has remained limited to the government's will and not paying any attention to the government responsibilities. To hide their activities and non-transparent operations, government have even passed some laws in their favor. This paper discussed how and why transparency \& freedom of information is necessary for the people of Pakistan and what policymakers can do in this regard. There is no concept of good governance without transparency in the operations of government.

The implementation of laws by the government lacks transparency rather it signifies restrictive operations. External parties become illegitimately involved in state affairs and government pay no heeds to it because of high dependency on them. Obviously, with the strong involvement of external parties, there will be no insurance of good governance and transparency (Mohmand \& Cheema, 2007). 


\section{Nature and Intensity of the Problem}

The problem under discussion in this paper is the right to freedom of information that should be accessible to the people of Pakistan to be aware of their government actions. The violation of the public's right is due to absence of legal regulation for it. The public laws are not enough to protect this right, and owing to this reason, government can easily go against the interests of the public. Therefore, there is a strong need for imperceptible and circulated policy, which can simplify and communicate this right to the public of Pakistan and make it easy to implement. It seems very easy, but the problem does not end here. If the incumbent or the next government will do it, there will be more threats than advantages of this right (Haiderud Din \& Ghani, 2011). The policy of this nature, which advocates transparency and freedom of information, would be different from all other existing policies and regulations and it would be challenging to regulate transparency because there was no such policy in the past and the public may be unaware of it. Its' sole purpose should be to ensure good governance and improve public sectors. In addition, it would create a strong bonding between the public and government, which is necessary for any prosperous state.

People of Pakistan have more trust in the military than the political parties, which is why the parliamentary institutions formed by the elections with the consent of the public are not strong as they should be. The people are expecting the government to do everything. They do not take any interest in participating in politics rather they only like discussing and observing government activities, which gives the authorities more freedom to go against the public interest. It promotes non-transparent and non-participatory governance (Rose \& Peiffer, 2018).

Pakistan is eager to provide the public freedom as per Islamic teachings and a welfare society where transparency prevails. Nevertheless, unfortunately, until the current date, no government was able to make a strong relationship of understanding and trust with the public. The Pakistani nation has always been concerned about spending public funds, exploiting national assets, shabby public infrastructure, and increasing corruption in all the sectors and departments of government. These significant problems create a culture of non-transparency in government operations (Mohmand \& Cheema, 2007). Over time, these problems went from bad to worse rather than any slight improvement. Transparency International conducted a survey in 2005 and results were flabbergasting. This survey ranked the countries around the world based on the Corruption Perception Index, means this index measured corruption in every state. Pakistan ranked 144 out of 158 countries, indicating it could not even reach the average level.

From 1995 to 2005, various governments and authorities tried to control the pervaded corruption and make anti-corruption laws, yet they experience a downfall in the Corruption Perception Index. The following table consists of the corruption perception index observed by the Transparency International Pakistan.

\begin{tabular}{|l|l|}
\multicolumn{2}{c}{ Corruption Perception Index } \\
\hline Years & Corruption perception index \\
\hline 1995 & 2.25 \\
\hline 1998 & 2.7 \\
\hline 2004 & 2.1 \\
\hline 2005 & 2.1 \\
\hline
\end{tabular}

The chart has taken by Transparency International Pakistan.

These figures are revealing that the CPI went down over the period of time, indicating that the transparency was improved. The improved transparency situation inhibits the efficiency of measures taken by the government in which administration and prosecution were involved to make trials and examine bureaucrats and officers. As a result, the corrupt officers and authorities were held accountable. However, this was not a massive change, but it gave some positive results, which is a hope for government and policymakers who want to devise measures for transparency in operations (Mohmand \& Cheema, 2007).

\section{Causes of Prevailing Culture of Secrecy Poor State of Governance in Pakistan}


The term governance includes all the activities and operations that the government is responsible to perform for the governed people. It creates a relationship between the government and the public. Poor governance explains the state of government in which duties were not performed efficiently as it was supposed to, and it cannot satisfy the public. It is a widely discussed topic and common concern of underdeveloped countries and countries with high poverty rate (Rose-Ackerman, 2005). Governance is entirely dependent on the decision-making of the authorized parties, and the consequences of these decisions decides whether it is good or bad governance. Several factors influence other factors like economic policy and democracy. Violation of public rights in any government is called lousy governance. Good governance stands for the government's ability and capability to make efficient decisions for public interests (Haider-ud Din \& Ghani, 2011). Various conditions and situations make the governance terrible, for instance, corrupt authorities, deception, and policies against the national interest. It is usually dependent on the international settings and structure for the government in the state. At some points, it becomes necessary for the government to meet the general public's expectations because ultimately, they hold the power to elect a government to govern (Kurd, 2021).

Various factors contribute in bad governance, including low accountability, political instability, and corruption. Pakistan has a poor level of accountability as the authorities are usually not accountable for their power usage. The corrupt bureaucrats are running the government. They have no interest in the welfare and growth of the state. The expenditures of a government are higher than the affordability of the country. They are using national assets and resources for personal needs and involved in nepotism. People have to pay even for their basic needs (Abdur Rahman, 2011).

\section{Lack of Access to Information}

The public should have access to the information of government as it is one of the fundamental principles of a good governance. The access to information will allow people to know about opportunities for employment and growth provided by the government solely for the state's welfare. It is a significant initiative against sustainable poverty in Pakistan (Randel, 2013 ). Access to information relates to power given to the media and journalists to preview the information, understand the technical aspects, and share it with the public. This access to information is necessary because in majority of the situations, governments prefer to hide information that could raise questions on their governance and safeguarding national interest. If access is restricted, then people will remain in the dark about state affairs, and the government will use its' power to exploit the public. The lack of transparency in National commissions and campaigns culminated into restriction of access to information. In Pakistan, all the government advocates freedom and independence of the media, but on the other hand, their latent agenda is to restrict the freedom of media (Randel, 2013 ).

The regulation of freedom of media raise questions on the government's performance and its commitment to the freedom of speech and expression. Freedom of speech is a fundamental right in the democratic states. It is the responsibility of the election commission to make the record and data available for access to the general public and media (House, 2016). Pakistan is a developing country, its' institutions and departments are struggling to make the database available on the internet, but the majority of their record is still in registers and documents. The insufficient resources and technology are hurdles in the availability of the e-database. Secondly, the public authorities are trained and experienced in old data management approaches, they lack adequate information pertinent to advanced equipment (Tochukwu, 2012).

\section{Non-Participatory Decision-Making Process}

Another reason for the lack of transparency in government operations is the non-participation of the public. Government is the sole authority of making and approving the decisions. Citizens have no participation in it. For example, the government approves and makes all the budgetary decisions that protect governments' interest rather than national interest (Zulfqar, Valcke, Devos, Tuytens \& Shahzad, 2016). The government acknowledges the need and right of the public in decision-making process, but no initiative has been taken on the pragmatic level. Government authorities are aware that the public will not take any action in response to any of their decisions that may harm the national interest. That is why they are avoiding transparency in government operations. People have no 
political education about their rights of participation in decision-making process and the corrupt governments takes advantage of it (Siddique \& Nawaz 2019).

The public is unaware that government cannot exercise power in every domain without the consent of the public. It is not a matter of concern for the Pakistani nation. There is no general awareness about it, which becomes a root cause for the non-transparency in the government operations. In other developed countries, public is well informed about the political matters and therefore they participate in political decisions to increase transparency, whereas, in Pakistan, people lack any such information (Buledi, 2020). They do not know how to hold government accountable for their corrupt actions. One significant area for the participation of the public is budget decisions. People of Pakistan can discuss the budget and fiscal distribution, but they are non-familiar with the technical aspects of budget making process. They do not have access to comprehensive information about these matters. In some areas, like the Punjab and KP governments are trying to enhance the public's participation and awareness of budget allocation through communication. They initiated the program of easy budget translation, in which information is easy to understand for those people who are unaware of the technical jargons (Alam, 2015).

\section{Non-Functioning of Democratic Institutions}

The democratic institutions in Pakistan are unable to perform their duties and functions independently due to political influence. Pakistan has a parliamentary democratic system and being a Republic democratic state, it experiences problems in establishing a sustainable democracy. The democratic institutions are failing in conducting fair elections. Free elections are necessary for the progress of democracy. It gives the voting right to citizens of Pakistan to elect any party or individual they consider appropriate for the position. All the citizens have an equal right to vote for any of the candidate or party. No institution and no political party should interfere with their rights. Unfortunately, people are unaware of the significance and responsibility of this voting right. They either do not cast vote or sell their votes, and resultantly, fair elections remain a pipe dream to hold (Buledi, 2020). The government formed based on such elections will not be capable of providing justice and transparency. If democratic institutions adopt transparency in their operations, they will enjoy good governance. We can say that fair elections are the basic criteria for having good governance. People can vote for any other party if they think one party do not meet their expectations (Bora, 2010).

Democratic institutions are the oxygen of democracy, which means they are responsible for good governance. The nonfunctioning of these democratic Institutions is the primary reason for the non-availability of the information to the public. The people working on official positions in these Institutions prefer their personal interests over public interests. They play an equal role in depriving people of their fundamental right to access information. The entire concept of democracy is dependent on the fairness of these departments (Bora, 2010).

\section{Information Disclosure and Identification of the Problem}

Understandably, the policy of the government depends on the principle of secrecy. They have to keep the secrecy for the national interest and national security. However, the concept of information disclosure is a separate thing. The regulations which limits the freedom of information are not acceptable at all. These laws violate the freedom given by the state to access the information about performance and actions of the governments. The corrupt authorities took advantage of it and national growth remains suffer. This paper suggests to make information related to government performance be available to the public and that should not raise concern on national security. Only disclosing the information and making it accessible to the public is not sufficient for freedom of information rather, government bodies are liable to convert this information in an easy-to-understand way. The sole purpose of both transparency and freedom of information is to enable the public in participation of decision-making process. However, the regulatory bodies restrict the population to access information by arbitrarily denying their rights. It is an actual problem here. Solving this problem requires attention from policymakers, Democratic Institutions, and regulatory bodies.

\section{Developments and Initiatives Local Government Ordinance}


The Local Government Ordinance 2001 advocates the freedom of information and transparency in government operations. It says that the government bodies are responsible for asking and consulting the public even if the matter is related to the assignment of tender contract to any private organization or any bigger issue that involves public interest. All the Zillah Council meetings will be open for public and the public will have a right to know about things discussed in those meetings. The record about social-economic surveys and the data collection will be the responsibility of the union administration. The local government will publish details of its' expenditures and incomes on a quarterly and annual basis. It must include all the information related to the public expenditure and welfare. This ordinance gives public an opportunity to know about any of the union administration, Tehsil municipal administration, and district government. It is the right of all citizens without any discrimination. This ordinance clearly shows that the regulations available in Pakistan advocate transparency and freedom of information to citizens. It also included some sections about revealing the information and details related to the performance of staff working there. There will be standardized forums on which information will be released and its' access to the public will be possible (Ali, 2006).

\section{Freedom of Information Ordinance}

The freedom of information ordinance was passed in 2002 by the President of Pakistan. Its' objectives were to ensure transparency and freedom of Information in Pakistan, so that the public can have access to any information related to the operations of the government and will help in evaluating government's performance. This ordinance makes the government accountable to its' citizens. However, it is not adequately regulated and there was no proper implementation of this law. One major flaw in its' implementation is that it compromises the widely recognized principles of freedom of information legislation. The criteria it mentions to have information is not broad enough to give accountability power to the people. Rather than declaring freedom of information as a fundamental right, it asserts that it must be designated by the constitution. The sole purpose of this ordinance is giving right to information to public in order to make them aware of their rights regarding having access to public records. This ordinance is not applied on district and provincial governments. It will only make the Federal Government's public bodies transparent. However, this ordinance denied access to some records and it was observed that this ordinance does not promote transparency rather its' latent objective was to favor the governments to keep hiding the public records (Ali, 2006).

\section{Functioning of Public Departments}

The Government of Pakistan tried to promote transparency and freedom of information through various regulations and laws, for instance, the local government ordinances 2001 directs the government departments about transparency in their operations and public participation in the functioning and decision-making of district and union administration. In 2002, the government also introduced the local government Ordinance 2002, which assures the freedom of information. It gives citizens the authority to make the government accountable by accessing the records and information of Federal public governments. It was the first freedom of information law regulated in South Asia. The public departments have to follow these regulations for transparency of their operations. The thing recognized and accepted all across the world is that transparency is dependent on accountability. All the public departments would become transparent and fair in their operations if they have a strong body for accountability, just like the National Accountability Bureau (Ali, 2006).

\section{Involvement of General Public through Local Governments}

Local government can involve the general public through implementing and regulating the LGO 2001. This regulation directs the local government to share the details about their performance to public through communication channels like media where people can easily access them. It indicates that the provincial governments also need to know about article 137 and the freedom of information. It does not facilitate GRMs (grievance redress mechanism). The deficiency in this ordinance is that it failed to provide guidance and direction to the general public about the actions they should take if the government refused or fail to share information (Ali, 2006).

\section{Policy Recommendations}


- There is a strong need for accountability. The national accountability bureau should be made independent in its' operations so that no external party or political pressure can influence them.

- There is a need for a uniform national policy favoring public interest over the government. This policy should be efficient enough to differentiate secrecy from freedom of information. This policy can be devised by modifying existing laws that limits the freedom of information. This policy should be well communicated; all the vocabulary and terminology used should be thoroughly explained so that the public can precisely understand every jargon.

- This policy should be in line with the principles of freedom of information and it should be strong enough to regulate all over the Pakistan.

- It should be applied to all the government bodies, including federal, province, and district, including ministries and public departments. It is important to note that the private entities funded partially or entirely by the government of Pakistan will also comply with this policy.

- The policy should include the digital database and records. In addition, it should understand e-governance, networking, and data centers.

- The policy should promote cost-effective measures of disclosing and keeping data through using latest technology. In addition, the staff of public bodies and government departments must be trained to utilize resources.

- The government should be fully committed to good governance. The civilians should be aware of their freedom of Information and transparency rights and they should know how to make government accountable.

- There is also a need for decentralized policy reforms including the authorities and parties excluded from freedom of information ordinances, like the district and provincial governments. The executive order can utilize its' power for giving access to restricted information and records mentioned by the local governments' ordinance. For the sake of transparency, this ordinance authorizes the power and could be enacted (Ali, 2006).

\section{CONCLUSION}

The freedom of information and transparency is the fundamental right of the people. This right is highly violated in Pakistan. In this paper, the researcher has discussed the significant causes for violation of this right, including a nonfunctioning of the democratic institutions, poor governance, non-participatory decisions, and the lack of access to information. The information made available by the government in their public documents and official pages used technical jargons and the general public is unable to understand it. The media tries to communicate this information, but political parties exercise their influence to restrict them, which means the information people have access to through media is also lacks transparency. The people of Pakistan are unaware of their right of freedom of information. They are not familiar with the methods of accountability of government. Their illiteracy and unawareness compel them to expect everything from the government. The government exploit their rights due to lacking any proper system of accountability. The democratic institutions are also not working and fulfilling their responsibilities. Their management and employees are influenced by political pressure and personal interest. People of Pakistan can only enjoy good governance if they become aware of the freedom of information and government accountability. To amend this situation, the government needs to perform operations and device policies for making information of public records accessible to the public and ensuring transparency.

\section{REFERENCES}

Abdur Rahman, S. (2011). Issues in Governance: Revisiting the Root Causes and Impacts of Corruption and Mismanagement. ISSRA, 3(1), 1-67.

Ahmad, M. (2019). Lack of accountability escalates corruption: experts. Retrieved from; https://www.thenews.com.pk/print/47922-lack-of-accountability-escalates-corruption-experts

Alam, A. (2015). No participation. Dawn. Retrieved from; https://www.dawn.com/news/1225096

Bora, N. (2010). Pakistan as Struggling Democracy. The Indian Journal of Political Science, 677-682. 
Buledi, Z. A. (2020). Space for the public. The News. Retrieved from; https://www.thenews.com.pk/print/761752-space-for-the-public

Escap, U. (2009). What is good governance? United Nations: Economic and Social Commission for Asia and Pacific. Retrieved from; https://www.unescap.org/resources/what-good-governance

Haider, A., ud Din, M., \& Ghani, E. (2011). Consequences of political instability, governance and bureaucratic corruption on inflation and growth: The case of Pakistan. The Pakistan Development Review, 50(4), 773-807.

Helms, L. (2012). Poor leadership and bad governance: reassessing presidents and prime ministers in North America, Europe and Japan. Edward Elgar Publishing.

House, F. (2016). Lack of access to information impacts the ability to report on Moldovan elections. Retrieved from Ifex: https://ifex.org/lack-of-access-to-information-impacts-ability-to-reporton-moldovan-elections/

Kurd, K. (2021). Lack of accountability in Pakistan. The Nation. Retrieved from; https://nation.com.pk/04-Nov-2017/lack-of-accountability-in-pakistan

Mcloughlin, C., Scott, Z. \& Haider, H. (2011). Communication and Governance: Topic Guide. (Revised ed.) Birmingham: GSDRC, University of Birmingham.

Mohmand, S. K., \& Cheema, A. (2007). Accountability failures and the decentralization of service delivery in Pakistan. IDS Bulletin, 38(1), 45-59

Randel, J. (2013 ). Why access to information needs to be central to the debate on poverty. The Guardian. Retrieved from https://www.theguardian.com/global-development-professionalsnetwork/2013/jan/18/mdgs-poverty-eradication-information-access

Rose, R., \& Peiffer, C. (2018). Bad governance and corruption. Palgrave Macmillan.

Rose-Ackerman, S. (2005). The challenge of poor governance and corruption, Revista Direito GV, 1 , 207-266.

Siddique, M., \& Nawaz, A. (2019). Effects of participative decision making on leadership styles: a student survey at Gomal University, Pakistan. International Transaction Journal of Engineering, Management, \& Applied Sciences \& Technologies, 10(11), 1-8.

Tochukwu, U. (2012). Problems of right to information access. Odessa Model United Nations Conference.

Zulfqar, A., Valcke, M., Devos, G., Tuytens, M., \& Shahzad, A. (2016). Leadership and decisionmaking practices in public versus private universities in Pakistan. Asia Pacific Education Review, 17(1), 147-159. 